\title{
MARCA-PAÍS: O CASO BRASILEIRO
}

Priscilla Thábata Alves da Silva*

\section{RESUMO}

O presente trabalho tem como objetivo analisar a importância da marca-país no contexto mundial no qual os países estão inseridos. Será apresentado o caso brasileiro levando-se em conta os aspectos positivos e negativos que representam o nosso país, uma vez que a marca Brasil deverá representar a imagem do turismo e das exportações brasileiras e buscar despertar o interesse de investidores internacionais. Após discutidos os conceitos fundamentais, será apresentada a posição do Brasil em relação a essa nova temática.

Palavras-Chave: Marca-País; Promoção das Exportações; Turismo; Marca Brasil;

\begin{abstract}
This work has the objective to analyse the influence of national brand in the world and the increase of the key factors in development. It will be studied the Brazilian case and the perceptions that already exists in the minds of others as an entity with positive and negative atributes, once that a positive national image is essential for export promotions and also for turism and investment promotion. After a revision of concepts and definitions considered basic for the intention of this work, I will intent to argue the Brazilian efforts to shape its brand if it has a clear strategy and the resources to go on.
\end{abstract}

Key-words: national brand; export promotion and tourism.

\footnotetext{
* Priscilla Thábata Alves da Silva é bacharel em Relações Internacionais pelo Centro Universitário de Brasília - UniCEUB. O presente artigo é parte integrante da monografia final de curso, cujo o tema é "Marketing Internacional e a Marca-País: o caso brasileiro.
} 


\section{Introdução}

O presente artigo se propõe a analisar como se desenvolvem as estratégias de implementação e sustentação de uma marca-país em mercados externos, sendo a estratégia de marketing internacional a forma como um país se prepara para competir em outros mercados.

A escolha do tema foi baseada na necessidade da presença brasileira ser cada dia mais forte e aparente no mercado internacional. Logo, o objetivo é descrever a forma adequada de apresentação da Marca Brasil utilizando as ferramentas do marketing internacional. A nova Marca Brasil foi desenvolvida por meio de pesquisas com turistas estrangeiros no Brasil, operadores internacionais de turismo e potenciais turistas no exterior, os quais definiram as principais qualidades brasileiras e as associaram às cores, que segundo eles, representam as características do nosso país.

Dessa forma, tenta-se explicar a importância das ferramentas do marketing internacional na criação de uma marca e de que forma elas proporcionam sua divulgação. Definiremos o que é a marca-país e a importância de seu posicionamento estratégico no cenário internacional como vantagem competitiva dos países. Serão analisadas questões como posicionamento estratégico e a situação atual da Marca Brasil de acordo com especialistas internacionais.

Percebe-se então que em um mundo globalizado, onde a competitividade entre os países é feita pelo processo de internacionalização, é de fundamental importância a escolha de um modelo estratégico de marketing, pelo qual, identificamos nossas limitações, o que nos permitirá compreender o comportamento dos concorrentes internacionais e a partir desse ponto concentrar esforços com vistas ao aprimoramento e desenvolvimento de nossas habilidades, a fim de que elas se tornem nossa vantagem competitiva no cenário internacional.

\section{Marca-País}

A marca-país é um ativo estratégico a ser utilizado por todas as nações com vistas ao fortalecimento e alavancagem do crescimento econômico. Muitos países, em especial países da América Latina, possuem imagens negativas frente aos consumidores e principalmente aos formadores de opinião internacional devido a características como poluição, narcotráfico, criminalidade e instabilidade política apresentada por essas nações. ${ }^{1}$ Problemas como esses vem sendo superados por algumas nações ao longo dos anos por meio de programas de construção e gerenciamento estratégico da marca-país que servem para melhorar a percepção do país em outros lugares e para atrair consumidores e investimentos internacionais. O gerenciamento eficaz de uma marca-país representa um dos fatores vitais para o crescimento de uma nação e para agregação de valor a seus produtos, uma vez que aumenta sua força e credibilidade no cenário internacional.

Para se destacar em um cenário tão competitivo e inovador, alguns especialistas como Philip Kotler e David Gertner sugerem que os países devem desenvolver esforços no sentido de administrar e controlar estrategicamente sua imagem validando-se de seus pontos de destaque e procurando corrigir as suas falhas. A criação de uma marca-país está

\footnotetext{
${ }^{1}$ S.N. Marca-País: ativo estratégico para alavancar o crescimento. HSM Management. São Paulo, edição no 44. maio/junho 2004. p. 61.
} 
ligada diretamente a relação de ajuda mútua a ser estabelecida entre o governo, o setor empresarial e os meios de comunicação.

O cenário internacional de hoje é caracterizado principalmente pela competição acirrada dos países em termos de imagem, cujo objetivo é a capacidade de superação na venda de produtos, capacidade de atrair investimentos, negócios e turistas. Nesse caso o governo e as empresas utilizam a ferramenta conhecida como "marketing estratégico de lugares" que tem a finalidade principal de promover a marca-país. ${ }^{2}$

A marca na atualidade é caracterizada como fator diferencial de competitividade nas mais diversas situações de negócios. A marca, como explicitado no capítulo anterior, é a forma de uma empresa ou organização prometer valor a seus clientes, transmitir emoções e influenciar comportamentos. A marca representa ativo estratégico de valor tanto para clientes como para investidores. Seu valor inclui fatores de qualidade de desempenho, fidelidade, garantia e principalmente de identificação frente aos outros produtos. No caso da marca-país, o valor emocional da marca está relacionado com a imagem que aqueles consumidores tem do país como um todo. O nome do país influencia na avaliação dos produtos e na decisão de compra. Diversas pesquisas mostram que muitos consumidores ao comprarem um produto, preferem aqueles de países industrializados devido ao valor que eles atribuem a marca-país representada naquele bem. ${ }^{3}$

Muitos setores da economia são responsáveis pela formação da percepção dos países, em especial os setores de meios de comunicação e entretenimento. Por isso muitas das associações feitas em relação aos países são apenas estereótipos criados consciente ou inconscientemente que em muitos casos não condizem com a realidade. Os estereótipos ou imagens dos países, assim como sua construção e definição podem ser difíceis de mudar, uma vez que os consumidores e os próprios investidores são resistentes a alterações de percepção mediante a fatos novos. Isso ocorre porque não há esforço para a correção de imagens previamente concebidas, o que dificulta o processo de mudança de percepção quanto aos países e falta de credibilidade quanto as possíveis inovações apresentadas por eles. ${ }^{4}$

Com o avanço das comunicações e o surgimento da necessidade de ser cada vez mais competitivo, se torna fundamental para os países a avaliação de sua imagem, ou marca-país, sobre o comportamento e a tomada de decisão dos consumidores. $\mathrm{O}$ fato de saber a origem de um produto é parte importante das avaliações, tornando-se em alguns casos tão relevante quanto o preço, nome da marca, pontos de venda e formas de comercialização, o que caracteriza que os consumidores em sua grande maioria, ao decidir comprar um produto usa as informações que possui a respeito do país de origem como forma de avaliar a qualidade do mesmo.

"...numerosas pesquisas parecem confirmar o impacto do "efeito país de origem" sobre o comportamento das pessoas em relação a produtos estrangeiros. E, assim, em muitos países, as autoridades de incentivo à exportação já admitem que a reputação nacional representa um ativo importante que precisa ser administrado." 5

\footnotetext{
${ }^{2}$ KOTLER, Philip; GERTNER, David. O marketing estratégico de lugares. HSM Management. São Paulo, edição $n^{\circ}$ 44. maio/junho 2004. p. 62.

${ }^{3}$ KOTLER, Philip; GERTNER, David. Op. cit. p. 62.

${ }^{4}$ Idem p. 63.

${ }^{5}$ Idem p. 66.
} 
O fato é que estarmos imersos em um mundo com mais de 191 Estados independentes, o que deixa claro que a riqueza de uma nação é fator determinante para a realização de negócios. O desafio do desenvolvimento e crescimento econômico passa a ser mais do que uma política de governo, tornando-se um desafio do mercado. Os países precisam ser atrativos e investir recursos para a atração de turistas, empresas e utilizar-se da estratégia de marketing de lugares para tornar suas exportações mais competitivas e administrar e formar consciente suas marcas. O marketing estratégico de lugares indica que os países devem avaliar sua matriz SWOT - Strenghts, Weaknesses, Oporttunities e Threats - , isso quer dizer que precisam descobrir seus pontos fortes e pontos fracos frente aos outros países, considerar as oportunidades e as ameaças oferecidas pelo ambiente, e suas forças competitivas por meio do monitoramento do mercado externo. Esse principio de atuação requer a ação conjunta do governo, das empresas e dos cidadãos. As ações a serem desenvolvidas por esses grupos devem buscar incentivos e influenciar a decisão dos consumidores na hora da compra por meio de suas vantagens, imagem, garantias e outros. As quatro principais tarefas de gerenciamento da marca-país são: 1) Administrar a imagem do país; 2) Atrair turistas; 3) Atrair empresas industriais e comerciais; e 4) Procurar novas oportunidades de mercado. ${ }^{6}$

A marca-país é o meio pelo o qual um país se comunica, se diferencia e simboliza suas particularidades. O desenvolvimento da marca-país requer um planejamento estratégico que procure avaliar a imagem da marca e perceber como ela se destaca frente as marcas concorrentes. A imagem a ser transmitida para o mercado internacional deve ser simples, atraente, gerar confiança e representar as características do povo que fazem parte daquela nação. Os países podem ser promovidos pela utilização de imagens, slogans, símbolos ou até mesmo se validar de certos lugares para se promoverem. ${ }^{7}$

Ao definir uma marca os gestores devem se preocupar com a idéia de país que irão passar, uma vez que transmitida uma imagem negativa, eles terão grandes dificuldades de reverter a situação. A atenção deve ser voltada principalmente as informações transmitidas pelos meios de comunicação para o resto do mundo, pois a difusão de informações é o que gera a criação dos estereótipos nacionais. Por isso, nesses casos, é aconselhável aos gestores que antes de tentar criar uma imagem nova para o país é preciso que se resolva os problemas que geraram sua imagem negativa. A criação de novas associações e imagens positivas são importantes para melhorar a imagem do país, mas de nada adiantam se não refutarem e solucionarem as falhas daquela localidade.

Segundo Kotler e Gertner muitas pesquisas apontam que as imagens dos países são indicadores importantes na avaliação de produtos e oportunidades de investimento, o que gera a necessidade de um gerenciamento de marca-país cada vez mais consciente. Os países devem então adotar as seguintes estratégias:

1) Analise e definição dos principais pontos fortes, pontos fracos, oportunidades e ameaças;

2) Seleção dos setores de atividades, personalidades e marcos históricos que forme uma base estratégica sólida da marca e uma narrativa interessante do país;

3) Desenvolver um conceito "guarda-chuva" que apresente e seja coerente com as atividades relativas ao desenvolvimento de sua marca;

\footnotetext{
${ }^{6}$ KOTLER, Philip; GERTNER, David. Op. cit. p. 68.

${ }^{7}$ KOTLER, Philip; GERTNER, David. Op. cit. p. 68.
} 
4) Destinação de fundos nacionais para as atividades relacionadas com a marca a serem desenvolvidas.

A implementação de um programa de marca-país quando bem estruturado tem o poder de realizar mudanças na imagem do país e serve como alavanca para o desenvolvimento econômico e a criação uma proposta durável de valor. ${ }^{8}$

Román Perez funcionário de uma das maiores firmas de consultoria do mundo em questão de marcas, a Interbrand, em entrevista exclusiva a revista HSM Management afirma que "criar e implementar um programa de marca-país é uma tarefa particularmente complexa devido à grande quantidade de empresas que precisam adotar as políticas de gestão de marca e à diversidade de público ao qual a iniciativa se dirige”.

Perez cita passo a passo o processo de criação e implementação de um projeto de marca-país ${ }^{9}$. A elaboração do projeto deve contar com a relação de comprometimento e de cooperação do governo, dos empresário, da comunidade e dos meios de comunicação. Para o autor a liderança do projeto deve estar nas mãos da organização que detenha maior peso e influência econômica, uma vez que a questão da liderança está associada diretamente a influência a ser exercida sobre as pessoas e as organizações que participarão do projeto de implementação, e nesse caso o consenso das partes é fundamental para o sucesso do programa.

No processo de implementação de uma marca-país é importante a utilização de ferramentas de análise da percepção do público em relação a uma nação, primeiramente considerando a percepção interna da identidade do país e identificando as características e qualidades que geram mais orgulho em seus cidadãos. Depois da análise interna, busca-se a avaliação de públicos externos destacando-se três grupos importantes: turistas, investidores e importadores. Nessa fase da pesquisa o fundamento é a busca pelas características mais atrativas para esses grupos. No caso dos turistas é importante considerar as suas percepções do país, as caraterísticas que mais chamaram atenção e o fator decisivo que os levaram a escolher o país como destino de viagem.

Os investidores são os grupos que influenciam na tomada de decisões de investimentos, tanto dos empresários quanto dos executivos que determinam o destino dos recursos das companhias. É importante identificar os fatores determinantes utilizados para formar opinião e canalizar os investimentos. Os investidores procuram encontrar lugares com alguns requisitos atrativos básicos: - política tributária com impostos moderados e bons níveis de serviço; - incentivos como profissionais adaptáveis a realidade; - Ambiente de negócios com parcerias duradouras; - Mão de obra e escolas qualificadas e de boa qualidade; e - Bons centros de pesquisa e desenvolvimento.

Já em relação aos importadores, a função principal é descobrir o que leva ou não a compra de produtos de um determinado país. Após a análise de cada um desses pontos, é desenvolvida uma estratégia que vise criar uma identidade para o país que será transmitida para os diversos públicos. Isso ocorre por meio do desenvolvimento da estratégia de posicionamento do país no cenário internacional com o objetivo de transmitir aos demais povos a idéia que aquele país possui o que eles procuram e precisam .

\footnotetext{
${ }^{8}$ PÉREZ, Román; organizadora ALONSO, Viviana. Um guia de implementação. HSM Management. São Paulo, edição $\mathrm{n}^{\circ}$ 44. maio/junho 2004. p. 74.

${ }^{9}$ PÉREZ, Román; organizadora ALONSO, Viviana. Op. cit. p. 74.
} 
A difusão das mensagem de uma marca-país podem ser feitas por meio de campanhas de comunicação de massa e exposição em lugares de intenso movimento. Essa comunicação deve ser feita de maneira uniformizada onde seja mantida a coerência da informação nos diversos meios utilizados para divulgação - banners, folhetos, cartazes e outros - e principalmente nas mensagem transmitidas aos órgão internacionais que transmitem a mensagem da marca para os demais atores internacionais.

Para Perez é importante que as entidades tenham em mente que a marca-país é muito mais do que um logotipo, pois ela deve abranger um conjunto de atividades que busquem um alcance mundial bem sucedido. A avaliação da marca-país deve considerar aspectos econômicos, relação das operações do país com o mercado externo, dados dos assuntos fiscais e buscar associar esses fatores aos demais pontos elencados com o objetivo de criar um projeto de marca-país abrangente.

Segundo Simon Anholt especialista em marketing de países, “ a marca é uma fonte de riqueza para um país e relaciona diversas estratégias para seu gerenciamento eficaz". ${ }^{10} \mathrm{O}$ desenvolvimento da marca-país no contexto mundial é fundamental para o crescimento econômico da nação e para o auxilio na distribuição de renda. Anholt afirma também que não adianta apenas a iniciativa governamental de criação e divulgação da marca no exterior, pois é importante a participação das empresas para a criação de marcas mundiais, da mesma forma que o apoio governamental é importante para às exportações. O especialista diz ainda que a promoção da imagem de um país deve ser um trabalho conjunto desenvolvido por todos os integrantes do programa, e destaca também que no caso brasileiro a imagem está associada principalmente à juventude, mas que a falta de criatividade e baixa auto-estima das empresas brasileiras são problemas que precisam ser solucionados com brevidade. ${ }^{11}$

Em entrevista a revista HSM Management, Simon Anholt analisa a questão de marca-país e os efeitos de um bom gerenciamento do programa. ${ }^{12}$ Anholt diz que a marca é uma poderosa ferramenta para o desenvolvimento uma vez que representa ativos intangíveis como reputação e imagem. Para ele a distância cada vez maior entre países ricos e pobres pode ser superada por meio de um gerenciamento eficaz de marca. É preciso que os países em desenvolvimento tenham consciência do que vem a ser a marca-país e da importância do seu gerenciamento para uma inserção mais competitiva e sustentável no mercado internacional. Os países precisam se destacar por seus valores de honestidade, transparência, um sistema político confiável e políticas fiscais justas.

"Uma imagem positiva contribui para a estabilidade da taxa de câmbio, aumento da influência na política internacional do país, estímulo ao crescimento das exportações de produtos de marca, atrai turismo e os investimentos." ${ }^{13}$

A marca-país permite maior competitividade aos países. Quando um cliente pensa em um país como marca, tem a tendência a relacionar os produtos e serviços daquela localidade com as informações pré-concebidas daquele lugar. Nota-se que a marca-país é o diferencial que agrega valor aos produtos e serviços de um país, sem tirar sua identidade ou

\footnotetext{
${ }^{10}$ ANHOLT, Simon; organizadora ALONSO, Viviana. Ferramenta para o desenvolvimento. HSM Management. São Paulo, edição n 44. maio/junho 2004. p. 88.

${ }^{11}$ Ibidem.

${ }^{12}$ Ibidem.

${ }^{13}$ ANHOLT, Simon; organizadora ALONSO, Viviana. Op. cit. p. 89.
} 
se sobrepor as características peculiares daquele bem. Dessa forma a marca-país ocupa a posição de ativo estratégico, fator diferencial na relação com o mercado.

No caso brasileiro, Anholt diz que o gerenciamento da marca ainda é um enigma. Isso acontece porque o especialista reconhece que o Brasil possui um dos principais atributos de competitividade no cenário mundial: a criatividade. Para ele a criatividade destaca produtos e agrega valor aos mesmos, fazendo com que eles pareçam mais importantes, tornando as empresas competitivas. No Brasil a criatividade se apresenta com freqüência nas artes, músicas e esportes, contudo não consegue ser utilizada de forma satisfatória no gerenciamento de marcas. As empresas brasileiras sofrem um grave problema de baixa auto-estima devido aos problemas econômicos já enfrentados pelo país e as dificuldades encontradas no processo de internacionalização.

Para Anholt, o governo brasileiro deveria ter o gerenciamento da marca-país como uma de suas prioridades, uma vez que o país tem uma boa imagem mas que infelizmente é ofuscada por alguns aspectos negativos, muitos deles devido ao relato de informações na mídia internacional. O Brasil possui um grande potencial natural favorável a sua imagem, mas que nem sempre é coerente com as mensagens emitidas. As campanhas de turismo contam a história de um país diferente daquele apresentado para o mercado internacional, principalmente no que se refere as políticas internas e internacionais. Para o especialista as empresas brasileiras possuem um grande potencial exportador associada a imagem Brasil que é muito forte. $\mathrm{O}$ que deveria se fazer nesse caso é buscar um projeto estratégico de marca-país que conte com o envolvimento do governo federal e dos demais setores empresariais, cujo o objetivo deve se focar na transmissão de uma imagem forte e uniforme do país. ${ }^{14}$

Segundo reportagem concedida a revista HSM Management, Fiona Gilmore presidente da Springpoint ${ }^{15}$, uma empresa de consultoria especializada em estratégia de marca e identidade corporativa, diz que na realidade todos os países já possuem alguma identidade fruto de associações feitas com o país, que podem ser negativas ou positivas. $\mathrm{O}$ desafio dos países é não se deixar identificar por um estereótipo negativo. Em muitos casos seu estereótipo, como já citado anteriormente, pode ser mais forte do que a realidade, e nesses casos os países possuem uma abertura para o estabelecimento de uma branding.

As variáveis positivas que compõe a imagem do país deverão ser exploradas no estabelecimento das marcas, e utilizadas como ferramentas de destaque no processo de comunicação. Elas devem representar a ideologia da marca e a identidade do país, por meio da utilização de logotipos, slogans, figuras, cores e outros. O país deve utilizar seus pontos fortes, como o patrimônio histórico, identidade cultural, aspectos naturais, a fim de estabelecer uma forma de identificação diferenciada das concorrentes e que conceda um diferencial competitivo e de destaque no mercado. Para Gilmore, a marca de um país deve ser baseada na utilização daquilo que já se possui e não uma invenção de fatores que busquem apenas a manipulação do mercado externo. O posicionamento do país não pode ser feito de maneira artificial, ao contrário, ele deve estar de acordo com a realidade e precisa unir as pessoas, e quando essa união de valores físicos, emocionais e espirituais é eficiente tem-se a chance de que essa conexão seja forte e poderosa.

\footnotetext{
${ }^{14}$ Idem p. 93.

${ }^{15}$ GILMORE, Fiona. Casos reais de sucesso. HSM Management. São Paulo, edição n ${ }^{\circ}$ 44. maio/junho 2004. p. 81 .
} 
Gilmore diz que quando bem definida e posicionada, a marca resiste ao tempo e as mudanças nos diversos setores econômicos, como a concorrência. Para esse bom desempenho, a marca precisa ser definida com base em estratégias de marketing que ajudem na adaptação e na garantia de que os produtos e serviços representados por ela cumprirão corretamente suas funções de acordo com as promessas da marca. Porém, apesar de todos os ajustes, a essência da marca permanece constante. Essa relação é estabelecida por meio dos valores que são importantes para aquela sociedade, assim como os fatores históricos, culturais, econômicos e experenciais.

O segundo ponto importante da marca-país é o posicionamento que o país terá por meio da utilização de suas variáveis. Essa é uma das partes mais complexas do estabelecimento de marcas, pois necessita de uma coordenação inspiradora, desafiadora e diferenciada para se destacar e inserir-se no cenário internacional. A marca-país não terá êxito se não conquistar seus clientes, além do mais as marcas podem ser facilmente esquecidas quando não representarem uma satisfação às vontades e desejos de um determinado público, e para manter-se bem posicionada precisará ser cativante. ${ }^{16}$

\section{Marca-País: o caso brasileiro}

No mundo globalizado torna-se cada dia mais importante o desenvolvimento de ações voltadas para a divulgação e fortalecimento da imagem de um país. Isso acontece porque a imagem de um lugar está associada diretamente as características de seu povo, a qualidade dos seus produtos exportados, a estabilidade oferecida por sua economia, seu potencial turístico e sua capacidade de atração de investimentos. A marca-país gera efeitos tanto externos quanto internos, pois além de permitir a uniformidade das informações e da imagem criada gera efeitos positivos para o mercado interno, como impacto no nível de renda e de emprego dos cidadãos que vivem naquele país.

A criação da imagem do país é uma tarefa difícil de se realizar, pois é composta de estratégias de médio e longo prazo, além de uma análise profunda que permita visualizar as fraquezas e potencialidades de um povo aos olhos dos estrangeiros.

"Os especialistas de marketing sempre tratam de construir uma imagem positiva para um produto ou uma empresa. Fazer o mesmo para um país é muito mais complexo, pois a percepção que se tem de um país reflete o conjunto de tudo o que acontece dentro de suas fronteiras, do que é divulgado no exterior e de como tudo isso é interpretado pela população dos diferentes países com diferentes culturas." ${ }^{17}$

O Brasil, dentro desse contexto, destaca-se por ser um país tropical com diversas características como: Modernidade (Brasília), Criatividade (futebol e música), Informalidade (jeitinho), Espontaneidade (calor humano, sensualidade), Alegria (carnaval, festas), e Cordialidade (hospitalidade e generosidade). Embora seja visto em outros países como um paraíso natural, infelizmente o Brasil ainda não tem uma imagem bem definida no exterior - ofuscada por fatos como a criminalidade, desigualdade social, irresponsabilidade, e preconceitos - o que deixa nosso país exposto a vulnerabilidade da

\footnotetext{
${ }^{16}$ GILMORE, Fiona. Op. cit. p. 83.

${ }^{17}$ APEX, Equipe. A primeira exportação a gente nunca esquece: como as empresas brasileiras estão chegando ao mercado externo - um relato de experiência da APEX. Rio de Janeiro: Qualitymark: APEX, 2003. p. 89.
} 
mídia internacional que nem sempre é realista e em alguns momentos transmite idéias e informações desfavoráveis ao Brasil. ${ }^{18}$

"É importante fugir dos estereótipos, dos preconceitos, das imagens irrealistas. Esta exigência não é apenas ética, por procurar uma comunicação correta e verdadeira, mas também é de oportunidade: a criação de uma imagem coerente com que é (e também com o que se poderá vir a ser no futuro) representa um caminho de desenvolvimento mais sustentável, comparado às imagens distantes da realidade". ${ }^{19}$

Segundo Fonseca, nossa imagem ainda está muito associada a estereótipos relacionados à natureza, futebol e carnaval, fatores essenciais da nossa cultura mas que não devem ofuscar ou limitar a utilização de outros aspectos pertinentes ao nosso povo e a nossa economia. O Brasil deve pensar estrategicamente a melhor maneira de utilizar de seus valores culturais para agregar valor as suas exportações e as suas empresas. Isso poderia ser feito por meio da utilização dos aspectos que gostaríamos de ter associados a imagem do nosso país - como qualidade dos produtos, modernidade e criatividade de nosso povo - coordenados a outros esforços junto aos demais atores internacionais - líderes políticos, mídia internacional, empresários e público - de forma a resultar na expansão do turismo para o Brasil e atração de investimento estrangeiro.

Nesse sentido foi desenvolvida a nova Marca Brasil, cujo a missão é definir uma identidade visual permanente para o Brasil no cenário mundial. A marca foi resultado de pesquisas com turistas estrangeiros, empresários e importadores, os quais citaram as características brasileiras mais marcantes como sendo os elementos representativos de nossa cultura e as associaram as cores, que segundo eles, representam o nosso país. "Os escolhidos respondiam perguntas sobre as cores características do Brasil, a comida, o motivo da viagem e, por último, resumiam o país em uma palavra", disse Edson campos, diretor de marketing da Embratur. ${ }^{20}$ No que se refere as cores, um dos itens de maior destaque da marca, a maioria dos entrevistados disseram que o Brasil é colorido, por isso a as cores escolhidas para a marca são: branca, azul, verde, amarelo, laranja e vermelho. O desenvolvimento desse projeto contou com a participação de instituições públicas e privadas que buscaram destacar a imagem positiva do Brasil. Participaram do processo de criação da Marca Brasil: APEX-Brasil, Embratur, ADG, SECOM, MDIC, Chias Marketing. $^{21}$

A intenção do programa é que os produtos exportados associem a sua imagem a imagem do Brasil, ajudando assim na promoção do nosso país. A marca pretende identificar o potencial turístico brasileiro e identificar os seus produtos brasileiros no exterior, por isso o símbolo é uma aquarela estilizada que transmite alegria e sinuosidade, características do povo e do território brasileiro. Essa será uma forma de agregar aos

\footnotetext{
18 FONSECA, Roberto Giannetti de. O Brasil e sua imagem no exterior. Disponível em < http://www.funcex.com.br/> Acesso em 31/08/05.

${ }^{19}$ Serviço Brasileiro de Apoio às Micro e Pequenas Empresas. CARA BRASILEIRA: a brasilidade nos negócios, um caminho para o “made in Brazil”. Brasília: Edição Sebrae, 2002. p. 13.
}

20 ABREU, Cláudia. $O$ 'made in Brazil' agora tem logomarca. Disponível em < http://www.anba.com.br/noticia.php?id=6229> Acesso em 30/06/05.

${ }^{21}$ APEX-Brasil (Agência de Promoção de Exportações e Investimentos); Embratur (Instituto Brasileiro de Turismo), ADG (Associação de Designers Gráficos), SECOM ( Secretaria de Comunicação de Governo e Gestão Estratégica da Presidência da República), MDIC (Ministério do Desenvolvimento, Indústria e Comércio Exterior), Chias Marketing ( empresa de consultoria internacional responsável pelo marketing turístico da Espanha. A empresa atuou na criação da marca da Espanha. 
produtos brasileiros uma diferenciação competitiva de qualidade, o que gerará ganhos mútuos, pois os produtos brasileiros ajudam na fortificação da imagem brasileira por meio das associações as marcas fortes de nosso país, tornando-o um atrativo de investimentos.

"Se valorizar e difundir seu patrimônio cultural, natural e humano levaram ... países a se destacar no mundo dos negócios, o Brasil pode se valer dessas experiências bem sucedidas e tornar a brasilidade um bem valioso na sua economia e nas suas estratégias de desenvolvimento." 22

O Brasil é identificado basicamente pela alegria de seu povo, identificada tanto nas festas quanto nas danças e músicas brasileiras. A nova marca tenta retratar a harmonia, alegria, a diversidade, a natureza e a modernidade brasileira, frutos das diferenças típicas e da miscigenação de nosso povo. A nossa marca é colorida, e é através das cores que tentará se mostrar aos resto do mundo as riquezas de uma nação jovem, exuberante e onde vivem pacificamente pessoas de várias raças e culturas. O Brasil será representado pelas cores e pela sinuosidade de suas curvas, afinal somos um país colorido, diferente, dinâmico e diversificado e nada mais justo do que utilizarmos nossas características como diferenciais competitivos e atrativos no mercado.

"A criação da Marca Brasil é indiscutivelmente um avanço no principal instrumento de visibilidade do destino turístico Brasil. Certamente vai ser um elo importante de ligação de todas as regiões do Brasil no exterior"., Allan Pires de Aguiar, secretário do Turismo do estado do Ceará. ${ }^{23}$

Porém, apesar de todos os esforços empreendidos para o fortalecimento da marca Brasil, ainda somos lembrados apenas como o país do futebol, da caipirinha e do carnaval, sendo esquecidos em muitas ocasiões que se referem a desenvolvimento tecnológico ou altos índices de modernização. Nesse sentido, a marca-país deve ser vista como um patrimônio atrativo do mercado que está acima da qualidade de produção nacional, das atrações turísticas, da capacidade industrial e dos bens históricos e culturais do país. A marca é a representação de todo o país, de seu povo, de sua cultura e de suas riquezas e por isso não deve ser má administrada ou esquecida. No entanto para muitos especialistas, o país destaque do futebol, esquece de gerenciar sua imagem deixando que ela seja ofuscada por suas falhas internas como a violência urbana e a pobreza nas favelas.

A marca Brasil deve coordenar a cooperação e o comprometimento de todas as organizações e setores envolvidos em seu plano. Ela pode destacar a imagem do nosso país no cenário internacional, agregando valor competitivo aos produtos exportados, tornando o país um lugar atrativo para os investidores e turistas internacionais. O Brasil é um grande competidor internacional, mas que não sabe usar sua imagem como vantagem competitiva para desenvolver seu crescimento econômico, e conquistar o espaço que lhe é merecido no cenário mundial. ${ }^{24}$

Segundo Athia ${ }^{25}$ - em sua reportagem para o portal AOL - o resultado do programa de uma marca-país pode variar de acordo com a organização do plano de trabalho, pesquisas sobre a imagem, estratégias de posicionamento da marca, plano de comunicação

\footnotetext{
${ }^{22}$ Serviço Brasileiro de Apoio às Micro e Pequenas Empresas. Op. cit. p. 8.

23 S.N. R\$ 12 milhões para promoção internacional dos Estados em 2005. Disponível em < http://www.unimonte.br/news/2302.asp> Acesso em 30/06/05.

${ }^{24}$ ATHIA, Guilherme. Brasil quer atrair investimentos, mas esquece de cuidar da sua marca-país. Disponível em < http://noticias.aol.com.br/negocios/industria/2004/07/0004.adp>Acesso em 28/09/2005.

${ }^{25}$ ATHIA, Guilherme. Op. cit.
} 
e comprometimento com o público. Porém um dos maiores problemas de desenvolvimento da marca-país é a dificuldade de decidir racionalmente o que é melhor para o país de acordo com os objetivos do mercado. Isso acontece por causa da acomodação gerada pelos grupos envolvidos no processo, que esperam que uma gestão política e emocional da marca-país seja o suficiente para sustentá-la. No caso brasileiro, o plano de trabalho da nova marca Brasil deve ser acompanhado diariamente a fim de avaliarmos se nossa marca atende às expectativas geradas no público; no entanto para que isso ocorra é preciso definir quais objetivos, estratégias, ações e resultados esperamos da marca. Para a marca-país os objetivos de médio e longo prazo são os mais pertinentes, uma vez que sabemos que o desenvolvimento da imagem de algum lugar no cenário global é algo que demanda tempo e esforços de posicionamento para que gere bons resultados.

O Brasil possui destaques de imagem positivos e negativos. Somos destaque de mídia internacional devido as viagens do nosso presidente, sucesso de nosso futebol, altos índices de pobreza e violência, escândalos políticos, cinema, música, belezas naturais, caipirinha, carnaval, novelas e muitos outros. Dessa forma, o Brasil deve repensar o seu posicionamento no cenário mundial e aproveitar suas vantagens como forma de construir uma imagem positiva de um país, que como qualquer outro sofre problemas, mas que nem por isso deixa de ser um bom lugar para se visitar e investir.

"O Brasil pode ser reforço de posicionamento de marca para determinadas categorias de produtos, para interesses específicos de turismo e pólo de investimento em atividades econômicas diferenciadas. O custo da ambição de se ter um gerenciamento da Marca-Brasil reside muito mais na ausência de coordenação dos interessados do que nos investimentos de um plano de comunicação ou na busca de sacadas geniais." 26

De acordo um estudo feito pela McCann-Erickson a imagem do Brasil continua ruim no exterior. O Brasil ainda precisa se empenhar muito para construir e fortificar sua marca, uma vez que a imagem brasileira é diariamente ofuscada por idéias como instabilidade econômica, violência, corrupção e pobreza. Porém, deve-se ter consciência de que tal posicionamento se deve ao fato de o Brasil não ser capaz de distribuir eqüitativamente suas riquezas entre o povo, por aparentarmos ser um país com jeitinhos e maneiras levianas e que em muitos casos facilitam o surgimento da corrupção.

Segundo a pesquisa, alguns dos principais problemas enfrentados pelo Brasil é o não-conhecimento dos brasileiros de seu próprio país e as informações transmitidas pela mídia internacional a nosso respeito. Nosso país é visto basicamente pelo clichê "país tropical" onde as pessoas costumam ver o Brasil como um país do futebol, de muita música, sol, praias e sensualidade, mas sem credibilidade e segurança a oferecer aos demais povos. O problema é que somos reconhecidos lá fora, mas não temos definido nosso lugar entre as marcas globais. ${ }^{27}$

Segundo as informações coletadas na pesquisa o Brasil pode ser uma marca-país forte e competitiva no cenário internacional, mas para que isso ocorra é necessário que sejam valorizadas as singularidades do nosso país de forma a se tornarem as nossas vantagens competitivas frente aos outros países, permitindo assim que nossa marca sirva de fomento a nosso crescimento e colocação no mercado internacional. Precisamos descobrir nossos valores mais profundos identificados pela marca a fim de sabermos colocá-la no

\footnotetext{
${ }^{26}$ ATHIA, Guilherme. Op. cit.

S.N. Imagem do Brasil continua ruim no exterior. Disponível em $<$ http://www.lagoinha.com/noticias/ver noticias.asp?codnoticia=16399> Acesso em 30/08/05.
} 
mercado e destacar nossos valores percebidos por outros no intuito de torná-los nossos pontos fortes de reconhecimento.

O Brasil, infelizmente, ainda oscila muito entre os pontos positivos e negativos de imagem apresentados ao mercado, pois se por um lado temos uma riqueza natural imensa, criatividade, hospitalidade, generosidade dentre outros, por outro lado somos vistos como um povo de baixa estima, país com distâncias geográficas entre os estados, país não confiável e instável político e economicamente. A McCann Erickson afirma em seu estudo que primeiramente os brasileiros - em especial aqueles que fazem parte da comunidade empresarial - tem que mudar a visão que eles têm a respeito do nosso país e esquecer esse ilusório complexo de inferioridade, pois somos um povo que possui um grande parque industrial, cheio de riquezas e recursos que devem ser nosso maior orgulho e nos dar orgulho de sermos brasileiros.

Para que o Brasil seja uma marca de sucesso é preciso que haja incentivo aos setores produtivos para que eles adotem um novo comportamento em relação ao mercado internacional, cuja a finalidade é aumentar a qualidade dos produtos e serviços brasileiros e as particularidades advindas de nosso país. A Marca Brasil deve servir de conexão entre os nossos pontos fortes e às necessidades e demandas dos consumidores de todo o mundo. Ao final da pesquisa, o presidente da McCann Erickson, sugeriu que fossem criados sites para dar cobertura a todas as questões de exportação brasileira, vídeos institucionais de nosso país à disposição de nossas Embaixadas, fornecimento de informações relevantes sobre o país as Embaixadas e apoio a eventos internacionais com o objetivo de mostrar e divulgar a nossa marca. Para o presidente da McCann Erickson nosso país possuem preços competitivos lá fora e os produtos brasileiros tiveram um aumento considerável em questão de qualidade, segundo ele "as marcas brasileiras ganharam evidência, mas ainda falta explorar mais os produtos de valor agregado".

\section{Considerações Finais}

Percebe-se que a marca-país é a representação de um povo cuja a imagem é a soma de seus valores, experiências e percepções dos consumidores frente a um país. A marcapaís é ativo estratégico importante que pode gerar impactos positivos ou negativos dentro de um mercado, e nesse sentido deve ser trabalhada a concepção de que a marca deve ser a representação da personalidade de um povo e das vantagens competitivas de um país de modo que alavanque o crescimento da economia gerando resultados positivos internos e externos. A marca deve ser obrigação não somente do governo, mas também de toda a classe empresarial e dos cidadãos, ela deve ter uma relação direta com seu povo e com os seus consumidores. Antes de destacar os pontos fortes e diferenciais no mercado, o país tem que corrigir seus pontos fracos e superar suas dificuldades, a fim de que eles não sejam sempre um obstáculo ao desenvolvimento e posicionamento do país.

Assim como as marcas são utilizadas pelas empresas, os países também podem e utilizam desse ativo estratégico para melhorar e fortalecer sua imagem no mercado internacional. A utilização de uma marca-país, é a forma como as nações se comunicam, se diferenciam e se mostram para as outras nações. A marca país é a forma de transmissão da imagem nacional com o objetivo e promover as exportações de um país, seu setor de turismo e atrair investimentos. A marca-país é muito mais do que um logotipo, pois abrange um conjunto de atividades que buscam um alcance mundial bem sucedido. Essa 
marca representa um diferencial competitivo para as nações, pois ajuda a agregar valor aos produtos e serviços de um determinado lugar sem que para isso o produto precise perder sua própria marca e qualidades.

No caso brasileiro percebemos os esforços feitos por parte de empresas privadas e do governo federal no que se refere a criação e fortalecimento de uma marca país. No programa "Plano Aquarela" lançado no começo do ano de 2005 com o objetivo de agregar valor e destacar as características do povo brasileiro, percebe-se a ação conjunta do setor público e privado no sentido de alavancar o crescimento das exportações, dos investimentos internacionais e do turismo brasileiro. No entanto, apesar de ser um plano com grandes dimensões e objetivos audaciosos, o esforço para fazer do Brasil um país atrativo para investimentos e turismo precisará superar os limites de alcance da nossa marca país.

Primeiramente é preciso que o governo se concentre em resolver suas crises internas e seus problemas como fome, corrupção e violência; pois o Brasil ainda é visto apenas como o país do samba, do futebol e do carnaval, que ainda não conseguiu resolver seus problemas políticos e sociais. Para que nossa marca supere os estereótipos negativos que circulam na mídia e no cenário internacional é preciso que ela seja acompanhada por um processo de reformulação de estratégias e desenvolvimento interno, que vise suprir as necessidades básicas do povo brasileiro como a fome e o fim da violência. A sociedade é o que dá vida a uma nação, e em um lugar onde as pessoas não respeitam os direitos básicos e fundamentais do ser humano, dificilmente será reconhecido por outros países como um lugar confiável e de credibilidade.

O programa de lançamento da nova Marca Brasil com certeza trará resultados positivos ao nosso país, pois destaca o que há de melhor em nossa terra e valoriza a cultura e o jeito de ser de nosso povo. Entretanto o governo, a iniciativa privada e a própria sociedade civil ainda terão muito o que fazer para que sejam solucionados nossos problemas internos mais urgentes, de forma que nosso Brasil com o passar dos anos possa ser reconhecido não somente por sua natureza e estilo de vida, mas que seja reconhecido também pelo desenvolvimento social e o fim da corrupção e da violência, dificuldades que hoje ofuscam e fazem de nosso país apenas mais um no cenário internacional.

\section{Referências Bibliográficas}

ANHOLT, Simon; organizadora ALONSO, Viviana. Ferramenta para o desenvolvimento. HSM Management. São Paulo, edição n 44. maio/junho 2004.

APEX, Equipe. A primeira exportação a gente nunca esquece: como as empresas brasileiras estão chegando ao mercado externo - um relato de experiência da APEX. Rio de Janeiro: Qualitymark: APEX, 2003.

GILMORE, Fiona. Casos reais de sucesso. HSM Management. São Paulo, edição n 44. maio/junho 2004

KOTLER, Philip; GERTNER, David. O marketing estratégico de lugares. HSM Management. São Paulo, edição n 44. maio/junho 2004. 
PÉREZ, Román; organizadora ALONSO, Viviana. Um guia de implementação. HSM Management. São Paulo, edição n ${ }^{\circ}$ 44. maio/junho 2004.

Serviço Brasileiro de Apoio às Micro e Pequenas Empresas. CARA BRASILEIRA: a brasilidade nos negócios, um caminho para o "made in Brazill". Brasília: Edição Sebrae, 2002.

S.N. Marca-País: ativo estratégico para alavancar o crescimento. HSM Management. São Paulo, edição no 44. maio/junho 2004.

\section{Internet (Webgrafia)}

ANBA

$\langle$ http://www.anba.com.br/noticia.php?id=6229>

AOL

$<$ http://noticias.aol.com.br/negocios/industria/2004/07/0004.adp >

FUNCEX

$<$ http://www.funcex.com.br/>

LAGOINHA.COM

$<$ http://www.lagoinha.com/noticias/ver noticias.asp?codnoticia=16399>

UNIMONTE

$<$ http://www.unimonte.br/news/2302.asp $>$ 